\title{
Wave-tilt characteristics of TE and TM-mode Waves
}

\author{
Ramesh P. Singh (*)
}

Received on August 20th, 1979

\begin{abstract}
Theoretical analysis have been carried out to investigate the effect of subsurface electrical parameters such as: resistivity and dielectric constant; and angle of incidence of electromagnetic waves on the amplitude and phase of the wave-tilt over a homogeneous earth model over a frequency range $10^{2}-10^{7} \mathrm{~Hz}$. Numerical results are presented for a wide range of above mentioned parameters. For better knowledge of subsurface features, need for wave-tilt measurement in TE and TM-mode have been discussed.
\end{abstract}

\section{RIASSUNTO}

Sono state esegute analisi teoriche per studiare gli effetti di parametri elettrici di sottosuperficie come: la resistività, la costante dielettrica e l'angolo di incidenza delle onde elettromagnetiche sull'ampiezza e la fase

(*) Department of Geophysics, Banaras Indu University, (Varanasi 221005, INDIA. 
della Wave-tilt, su un modello omogeneo della terra in un intervallo di frequenza compreso fra $10^{2}-10^{7} \mathrm{~Hz}$.

Si presentano i risultati numerici per un grande range di parametri suddetti. Per una conoscenza migliore della sottosuperficie è stata dibattuta a lungo la necessità di misure per Wave-tilt nei modi TE e TM.

\section{INTRODUCTION}

The measurement of wave-tilt as a diagnostic technique for studying the earth's subsurface properties dates back to the beginning of twentieth century (Zenneck, 1907; Hack, 1908). It was shown that the electric vector of Zenneck surface wave traced out a narrow ellipse which was tilted slightly forward. The theory of wave-tilt was further formulated for air-earth interface by Sommerfield (1926) and Norton (1937). The property of earth's surface has been studied by Barlow and Fernando (1956), Wait (1957) and Furutsu (1959). Thereafter a number of investigations on the characteristics and mode of measurement of wave-tilt have been reported in the literature (Wait, 1962; King, 1968; 1969, 1974, 1976; Lytle et al., 1976; Sinha, 1977). The increasing potentiality and popularity of the method has lead to its successful applications for resistivity mapping (McNeill and Hoekstra, 1973; Hoekstra and McNeill, 1973; Hoekstra et al., 1974, 1975; Arcone, 1977, 1978; Arcone et al., 1978; Hoekstra, 1978; Arcone, 1979 and Thiel, 1979).

The analytical study of wave-tilt amplitude and phase angle of radiowave reflected at grazing incidence from a given earth's surface model plays a very important role in the interpretation of experimental data. The master curves showing the theoretical response can be used to invert the measured wave-tilt data and obtain the electrical parameters of earth's surface.

The potentiality of the wave-tilt measurements in TM and TE-modes have been commented upon by King, 1974; Lytle and Lager, 1976; and Thornton, 1979. The main objective of the study presented in this paper is to decipher the characteristic wave-tilt features in both the TM and TE-modes and bring out comparative potentialities of measurements in the two modes. 


\section{WAVE-TILT FORMULAS}

Wave-tilt in TM-mode on the hogeneous earth's model in terms of normalised plane wave surface impedance is written as (King, 1969)

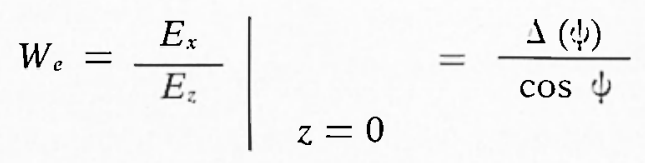

where

$$
\Delta(\psi)=\frac{1}{M}\left[1-\frac{\cos ^{2} \psi}{M^{2}}\right]^{1 / 2}
$$

normalized plane wave surface impedance

$$
\begin{aligned}
& M=\left(\varepsilon_{r}-\frac{\imath \sigma}{\varepsilon_{o} \omega}\right)^{1 / 2}, \text { complex refractive index } \\
& \varepsilon_{r}=\text { dielectric constant of the medium } \\
& \sigma=\text { conductivity of the medium } \\
& \omega=\text { angular frequency }(\omega=2 \pi f) \\
& \psi=\text { the angle of the incident wave makes when it is re- } \\
& \quad \text { flected from the earth's model }
\end{aligned}
$$

On grazing incidence, $\psi \rightarrow 0$ and the wave-tilt on the earth's model in terms of normalized plane wave surface impendance is written from equation [1] as

$$
W_{e}=\frac{E_{x}}{E_{z}} \mid \begin{aligned}
& z=0 \\
& \psi=0
\end{aligned}=\Delta=\vee \sqrt{1-\nu^{2}}
$$

where

$$
\nu=\frac{1}{M}
$$


For TE-mode waves, wave-tilt is defined as (Lytle, 1976)

$$
W_{m}=\left.\frac{H_{x}}{H_{z}}\right|_{\mathrm{z}=0}=M^{2} \frac{\Delta(\stackrel{\jmath}{\mathrm{\prime}})}{\cos \psi}
$$

Substituting for $\downarrow(\Delta)$ and writing

$$
\nu=\frac{1}{M}
$$

as before, we obtain an equation for TE-mode which analogous to equation [2]

$$
W_{m}=\left.\frac{H_{x}}{H_{z}}\right|_{\begin{array}{l}
z=0 \\
\psi=0
\end{array}}=\frac{\sqrt{1-\nu^{2}}}{\nu}
$$

\section{REsults AND Discussions}

Effect of angle of incidente, resistivity and dielectric constant

Numerical computations using equations [1] and [3] show the effect of angle of incidence, resistivity and dielectric constant on the amplitude and phase of wave-tilt for both TM and TEmodes. In Fig. 1 variation of the amplitude of the wave-tilt with angle of incidence $\left(0^{\circ}-90^{\circ}\right)$ for the resistive values 10,100 , $1000,10000,100000$ Ohm-meter at frequency $10^{4} \mathrm{~Hz}$ has been shown. It is observed that the magnitude of wave-tilt is larger in TE-mode than TM-mode. It is seen that with the increase of incidence, the magnitude of wave-tilt also increase in both the modes. It is further seen that for TM-mode, the amplitude of wave-tilt increases with increase in resistivity of the ground whereas reverse holds good for TE-mode. The phase of the wave-tilt variation with angle of incidence for resistivity value 


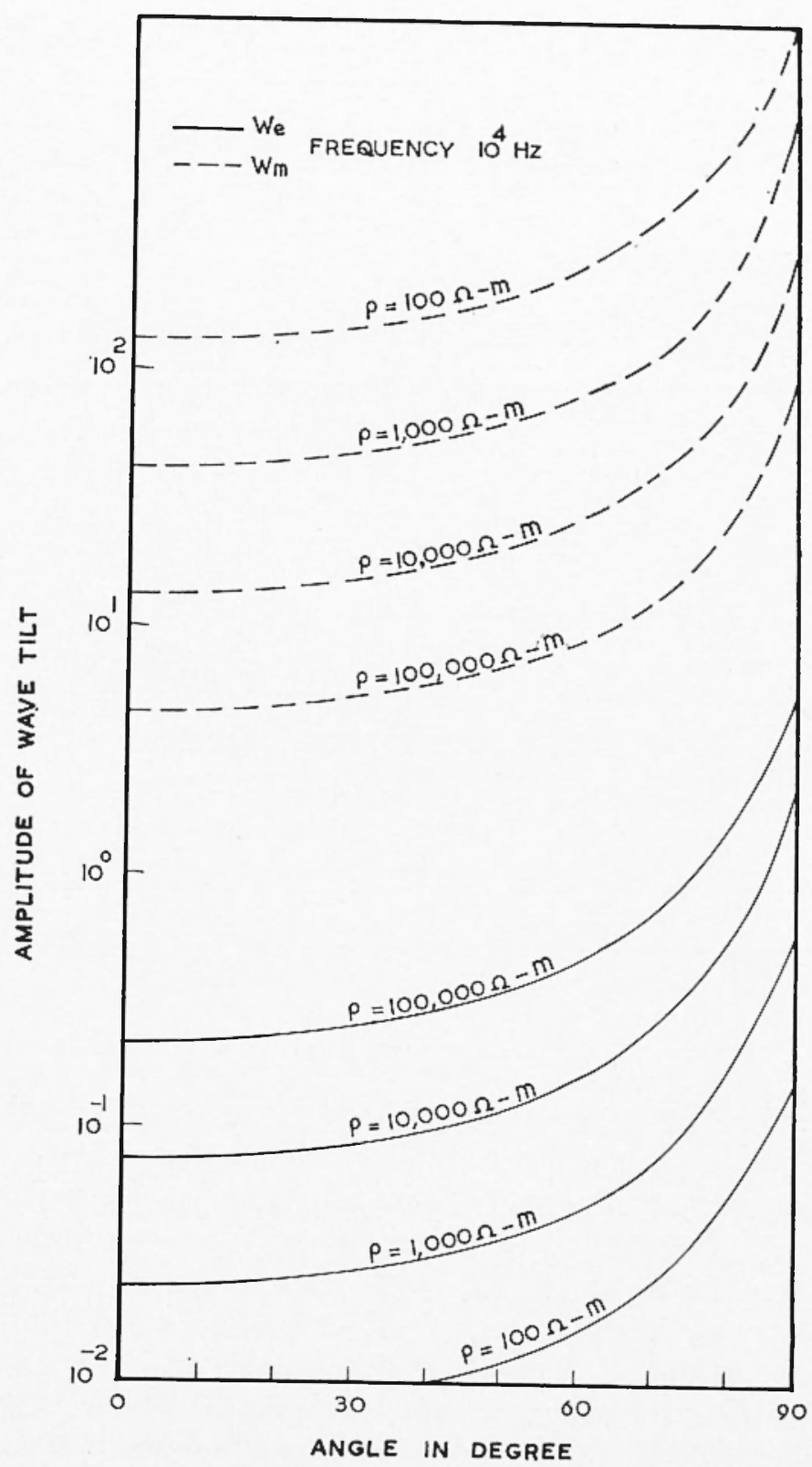

Fig. 1 - Variation of the amplitude of wave-tilt with angle of incidence. 


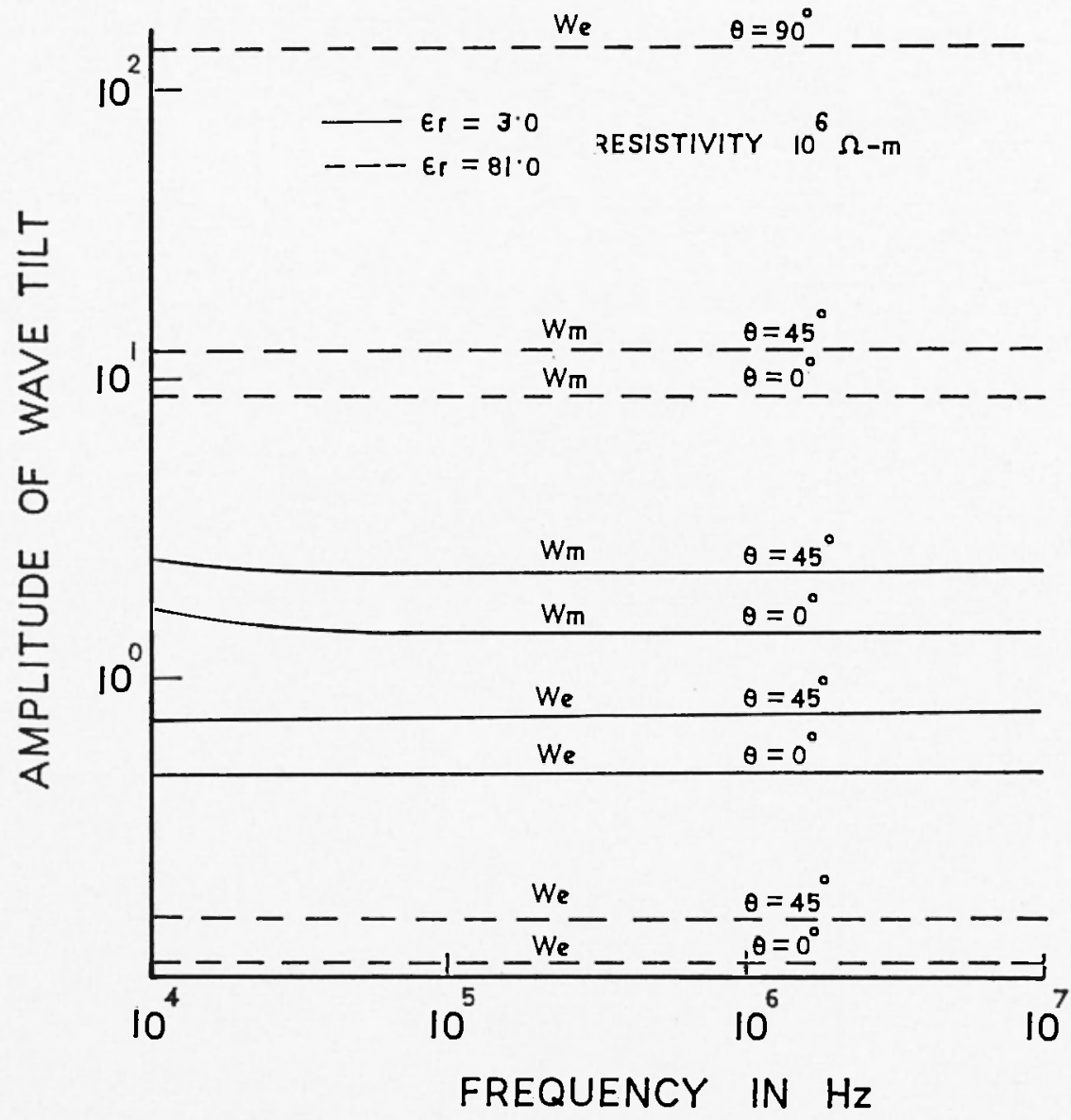

Fig. 2 - Variation of phase of wave-tilt with angle of incidence.

$10000 \mathrm{Ohm}$ meter at $10^{4}, 10^{5}, 10^{6} \mathrm{~Hz}$ are shown in (Fig. 2). It is seen that with the change in angle of incidence in both TE and TM-modes, phase of wave-tilt is not affected at lower frequency $\left(10^{4} \mathrm{~Hz}\right)$ whereas at higher frequencies $\left(10^{5}\right.$ and $\left.10^{6} \mathrm{~Hz}\right)$, the phase of wave-tilt is seen to increase for TM-mode but decreases for TE-mode with a small increase in angle of incidence.

The amplitude and phase angle of wave-tilt versus frequency 


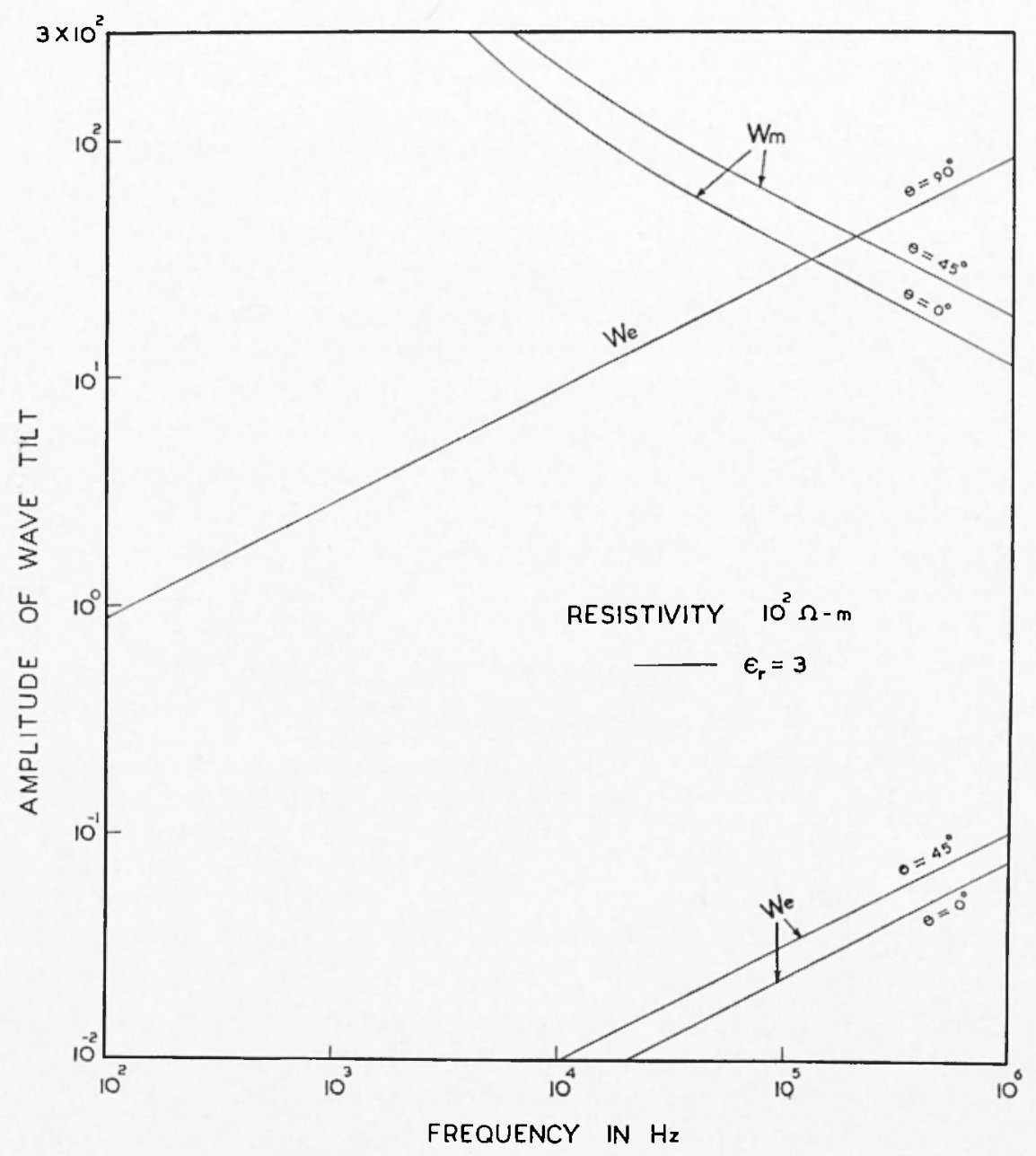

Fig. 3 - Variation of the amplitude of wave-tilt with frequency for resistivity $10^{2}$ Ohm meter.

for a resistivity value $10^{2} \mathrm{Ohm}-\mathrm{m}$, have been computed for TM and TE-mode waves and are shown in Fig. [3] and [4]. The amplitude of wave-tilt for TM-mode shows a linear increase with frequency whereas for TE-mode, a reverse trend is seen (Fig. 3). The amplitude of wave-tilt for TM and TE-mode attains higher values 
at higher angle of incidence, being much larger at $\theta=90^{\circ}$ as compared to $\theta=0^{\circ}$ and $45^{\circ}$ which are relatively close to each other.

The curve for $\theta=90^{\circ}$ for wave-tilt of TE-mode waves is not shown in the Fig. 3), because it is larger than $10^{2}$. At lower values of resistivity, the displacement current becomes much smaller and the dielectric constant variation loses its significance. The phase of wave-tilt and their variation with frequency for TM and TE-modes are almost mirror image of each other, with positive values for TM-mode and negative for TE-mode. The phases of TE and TM-mode waves are not affected by the change in the angle of incidence (Fig. 4) .The change of dielectric constant considerably influences the phase of wave-tilt. It is seen that for $\varepsilon_{r}=3$, the phase is $45^{\circ}$ unaffected by frequency, whereas
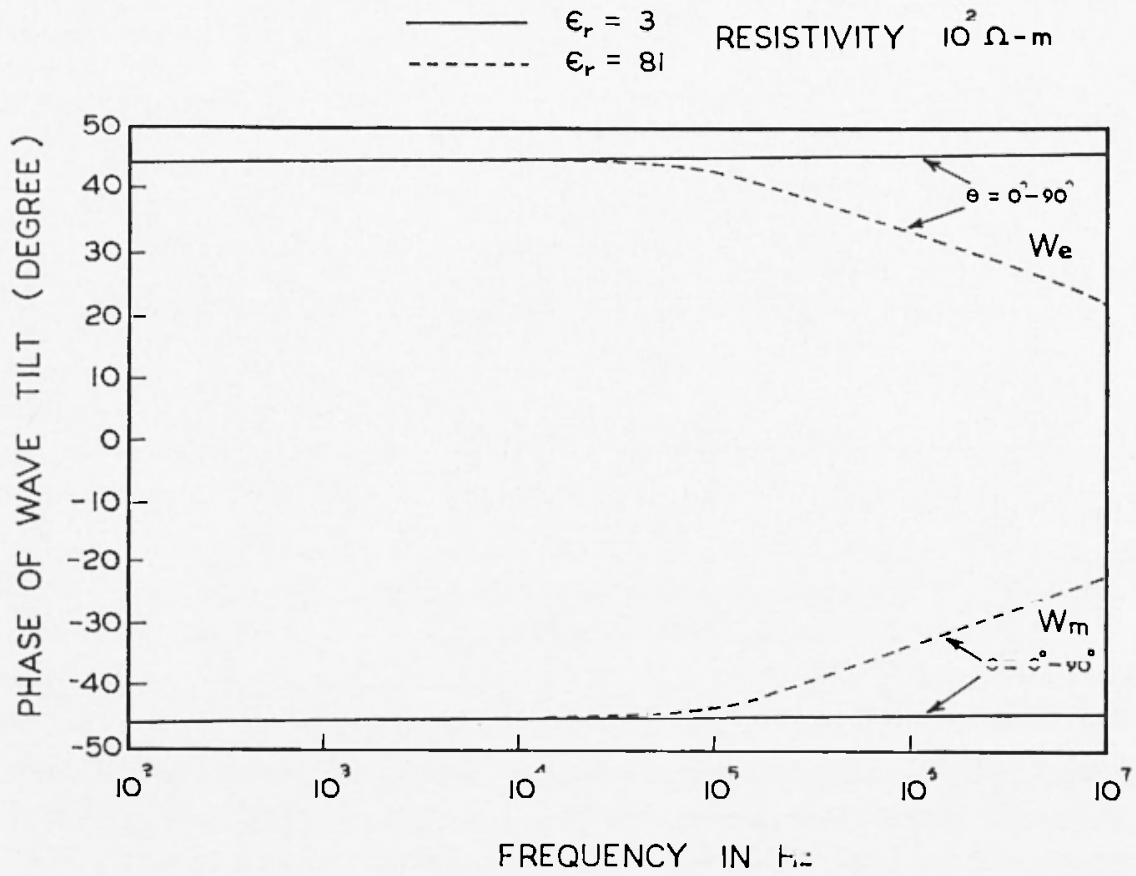

Fig. 4 - Variation of phase of wave-tilt with frequency for resistivity $10^{\prime} \mathrm{Ohm}$ meter. 


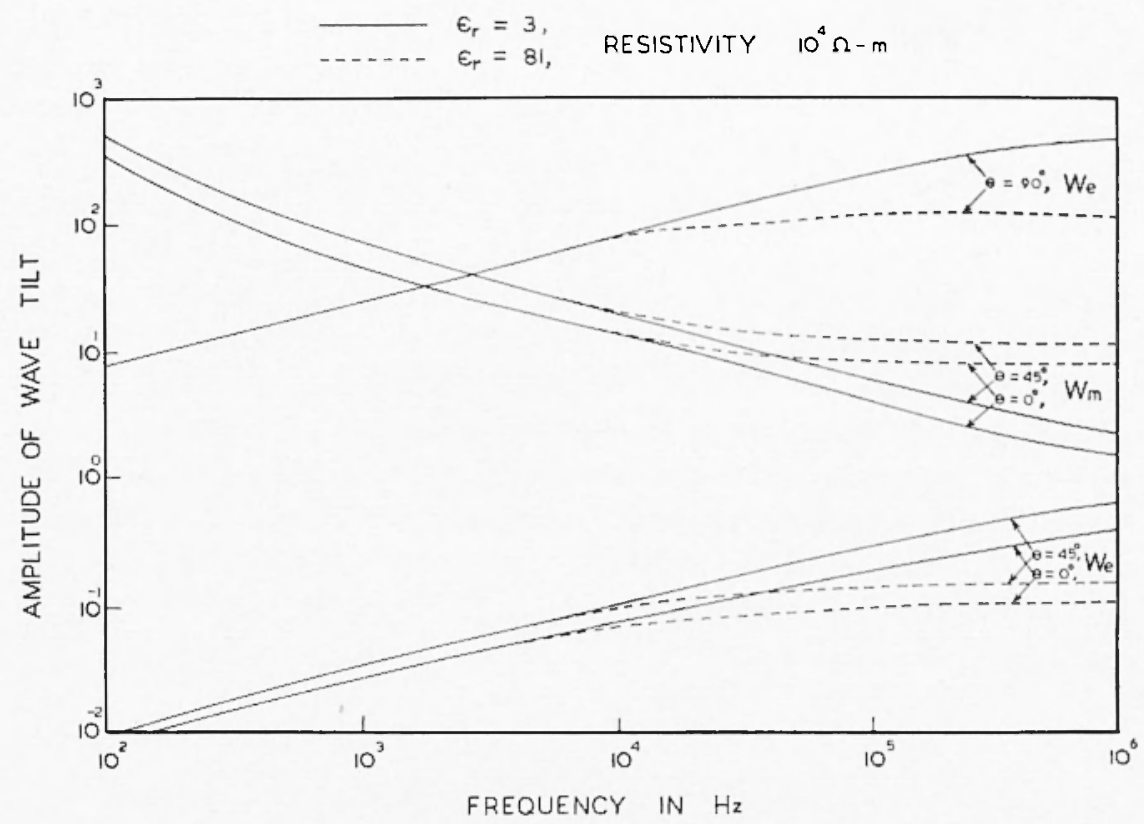

Fig. 5 - Variation of the amplitude of wave-tilt with frequency for resistivity $10^{4} \mathrm{Ohm}$ meter.

for $\varepsilon_{\mathrm{r}}=81$, phase changes from $45^{\circ}$ at $10^{4} \mathrm{~Hz}$ to about $20^{\circ}$ at $10^{6} \mathrm{~Hz}$.

Figs. 5 and 6 show the amplitude and phase angle of TM and TE-mode wave-tilt for the same values of parameters as in figs. 3 and 4 at a higher resistivity values of $10^{4}$ Ohm-m. The amplitude dependence on frequency and incidence angle show similar variaions as presented earlier. The effect of dielectric constant variation becomes distinguishable at higher value of surface resistivity. The amplitude of wave-tilt for TM-mode decreases with increase in dielectric constant, whereas it increases for TE-mode for all angles of incidence. In general magnitude of wave-tilt of TE-mode is higher than TM-mode for all angles of incidence. The wave-tilt for TE-mode for $\theta=90^{\circ}$ is large and is not shown in Fig. 5. The phase curves (Fig. 6) for TM-mode are mirror image of TE-mode and show a decreasing trend in 
phase angle with increasing frequency. For $\varepsilon_{\mathrm{r}}=3$, the phase angles for $\mathrm{TM}$ and $\mathrm{TE}$-mode at $10^{4} \mathrm{~Hz}$ start varying from $+45^{\circ}$ and $-45^{\circ}$ respectively and gradually decrease to zero degree phase angle at $10^{7} \mathrm{~Hz}$. For dielectric constant values 81 , the phase values are lowered showing $+35^{\circ}$ at $10^{4} \mathrm{~Hz}$ and gradually decrease to zero degree phase angle at about $10^{6} \mathrm{~Hz}$. It is observed that the phase values in general are higher for higher angle of incidence for TM-mode but in the case of TE-mode waves, the phase angles ar higher for lower angle of incidence. The difference in phase for variations in angle of incidence is, however, very small and can hardly be used as a diagnostic. The variation in amplitude and phase of TM and TE-mode for higher resistivity of the earth's surface do not show significant variations in amplitude and phase of TM and TE-mode wave-tilt. The variations of amplitude with angle of incidence and dielectric

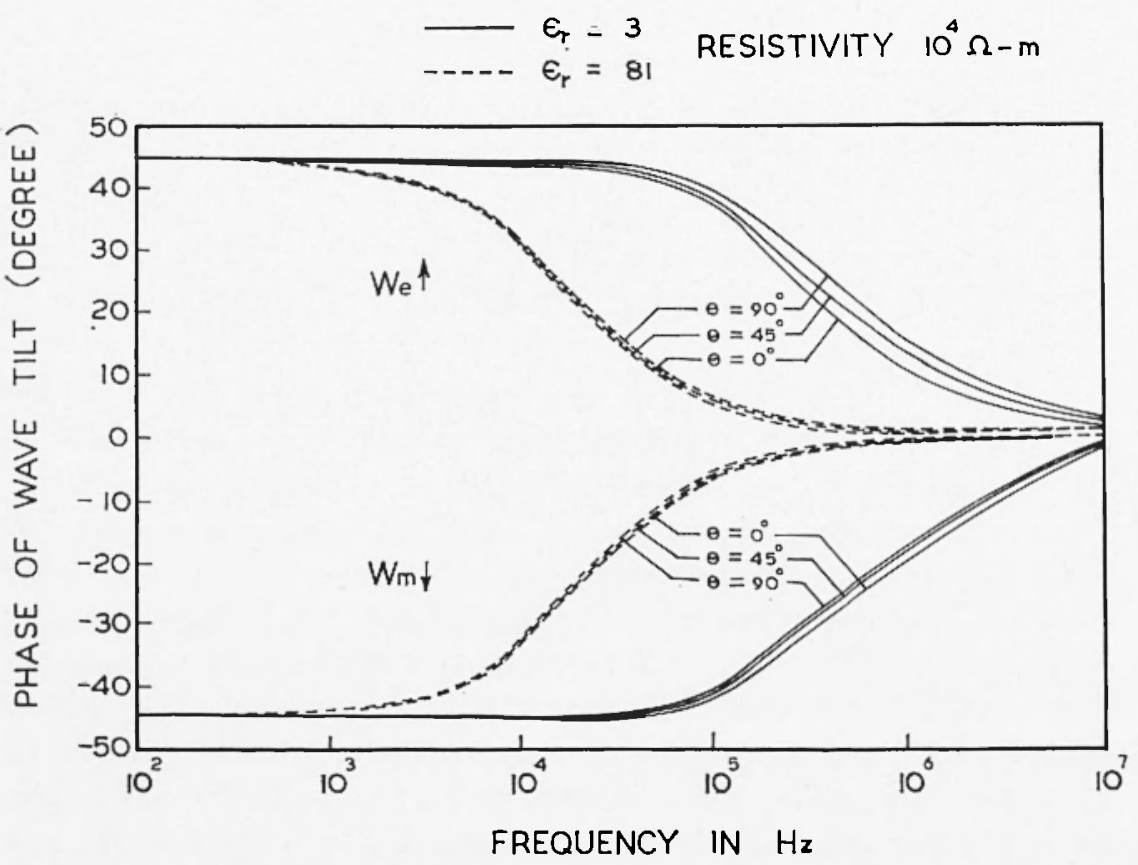

Fig. - Variation of phase of wave-tilt with frequency for resistivity $10 \mathrm{Ohm}$ meter. 


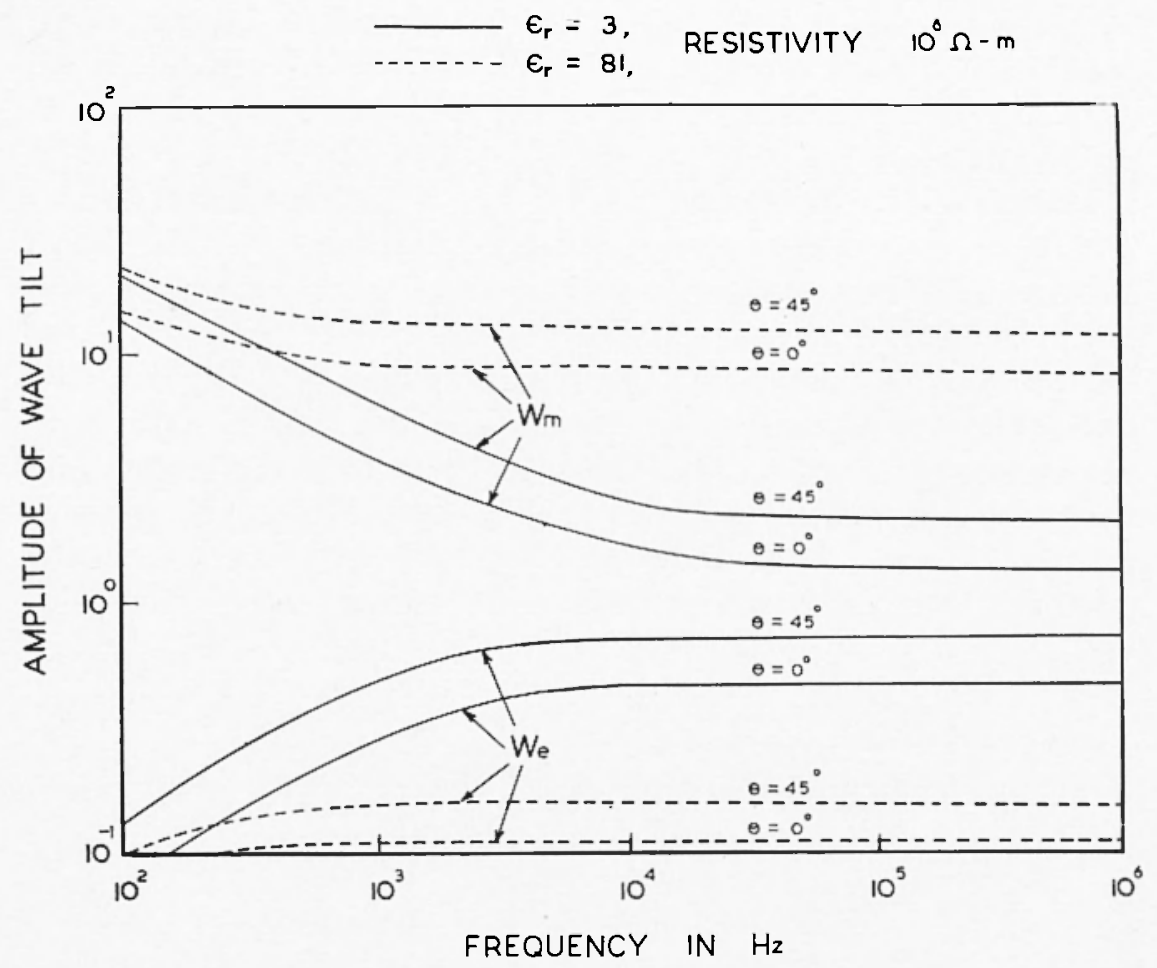

Fig. 7 - Variation of the amplitude of wave-tilt with frequency for resistivity $10^{6} \mathrm{Ohm}$ meter.

constant becomes more pronounced in higher frequency range but do not show any variation with frequency.

Computations carried out in figures 5 and 6 are repeated at a still higher resistivity value of $10^{6} \mathrm{Ohm}-\mathrm{m}$ and results are shown in figures 7 and 8 . The amplitude does not show any variation with frequency and remains virtually same at all the frequencies. The effect of dielectric constant is more pronounced showing appreciable amplitude differences at the same angle of incidence. The phase angle values are further reduced. It decreases from $45^{\circ}$ at $10^{2} \mathrm{~Hz}$ to about zero degree at about $10^{5} \mathrm{~Hz}$. For dielectric constant value 81, phase for all angles of incidence is close to zero degree at higher frequencies (greater than $10^{3} \mathrm{~Hz}$ ). 
Using equations [2] and [4] we have computed the wave-tilt magnitude for various practical resistivity values of the earth's surface. The variation of magnitude of $W_{e}$ and $W_{m}$ in the frequency range $10^{2}-10^{7} \mathrm{~Hz}$ are shown in Fig. 9. Two sets of limiting dielectric constant values 3 and 81 have been chosen with a view to demonstrate the wave-tilt response from earth's surface and the water surface. The variations for intermediate values of dielectric constants can be easily inferred from these curves. The $W_{e}$ curves for resistivity values $10^{2}, 10^{4}$ and $10^{6}$ Ohm-m show an increasing magnitude of the wave-tilt with increasing frequencies. At higher frequencies the wave-tilt produced by higher resistivity surface $10^{4}$ and $10^{6} \mathrm{Ohm}-\mathrm{m}$ becomes saturated and do not show any increase with increasing frequencies, especially between $10^{6}-10^{7} \mathrm{~Hz}$ as shown in Fig. 9.

$$
\begin{array}{cc}
\epsilon_{\mathrm{r}}=3 \\
\ldots-\cdots & \epsilon_{\mathrm{r}}=81
\end{array} \quad \text { RESISTIVITY } 10 \hat{\Omega} \Omega-\mathrm{m}
$$

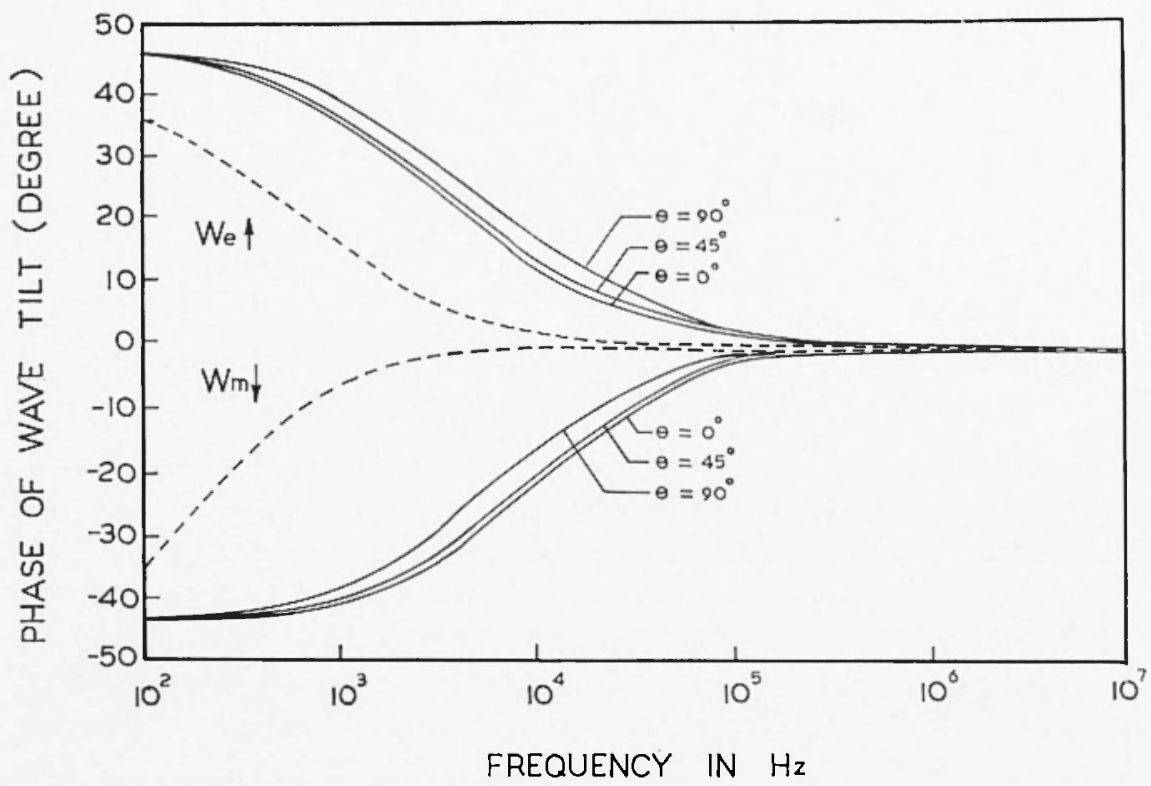

Fig. : - Variation of phase of wave-tilt with frequency for resistivity $10 \mathrm{Ohm}$ meter. 


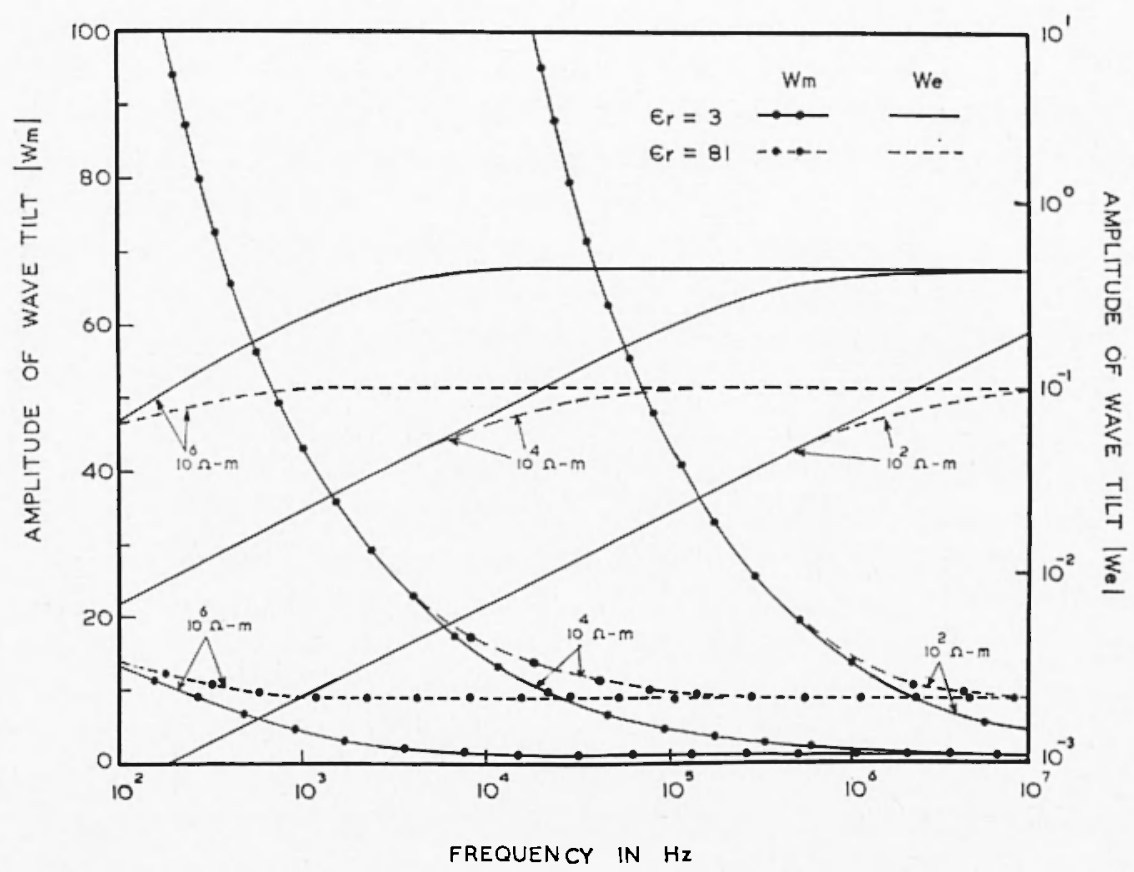

Fig. 9 - Variation of the amplitude of wave-tilt with frequency.

The phase angle variation of wave-tilt with frequency for some surface parameters has been shown in Fig. 10. The phase angle of $W_{e}$ decreases almost linearly in certain frequency range namely between $10^{3}$ to $10^{4} \mathrm{~Hz}$ for resistivity $10^{2} \mathrm{Ohm}-\mathrm{m}$ and dielectric constant values 3. For dielectric constant 81 , this frequency shifts to lower frequency range of $10^{2}-10^{3} \mathrm{~Hz}$. Similar decrease in the phase angle variation are also seen for resistivity value $10^{4}$ and $10^{6} \mathrm{Ohm}-\mathrm{m}$ and the phase angle change for dielectric constant value 3 and 81 are seen to consilerably large.

The corresponding values of magnitude and phase angle of wave-tilt $W_{m}$ have been computed and shown in Fig. 9 and 10 for the sake of comparison. It is shown in Fig. 9 that the magnitude of $W_{m}$ is almost two order o magnitude higher as compared to $W_{c}$ for dielectric constant 3 . The effect of higher 
values of dielectric constant 81 is seen only at higher frequency where the solid and dotted curves are seen to fork showing higher magnitude for dielectric constant 81. The magnitude of $W_{m}$ for resistivity value $10^{2} \mathrm{Ohm}-\mathrm{m}$ varies from $0-100$ in the frequency range $10^{4}-10^{6} \mathrm{~Hz}$, whereas for resistivity values $10^{4}$ Ohm-m the magnitude of $W_{m}$ varies from $0-100$ in the frequency range $10^{2}-10^{5} \mathrm{~Hz}$. For higher values of resistivity $10^{6} \mathrm{Ohm}-\mathrm{m}$ the wave-tilt response shifts still towards lower frequencies. The phase angle variations for TE-mode waves are negative as shown in Fig. 10. The phase angle variation for $W_{m}$ is between $-45^{\circ}$ to $0^{\circ}$, whereas for $W_{e}$ the phase angle varies between $45^{\circ}$ to $0^{\circ}$. For a given value of surface resistivity, the phase angle of $W_{e}$ decreases from $45^{\circ}$ to $0^{\circ}$, whereas the phase angle of $W_{m}$

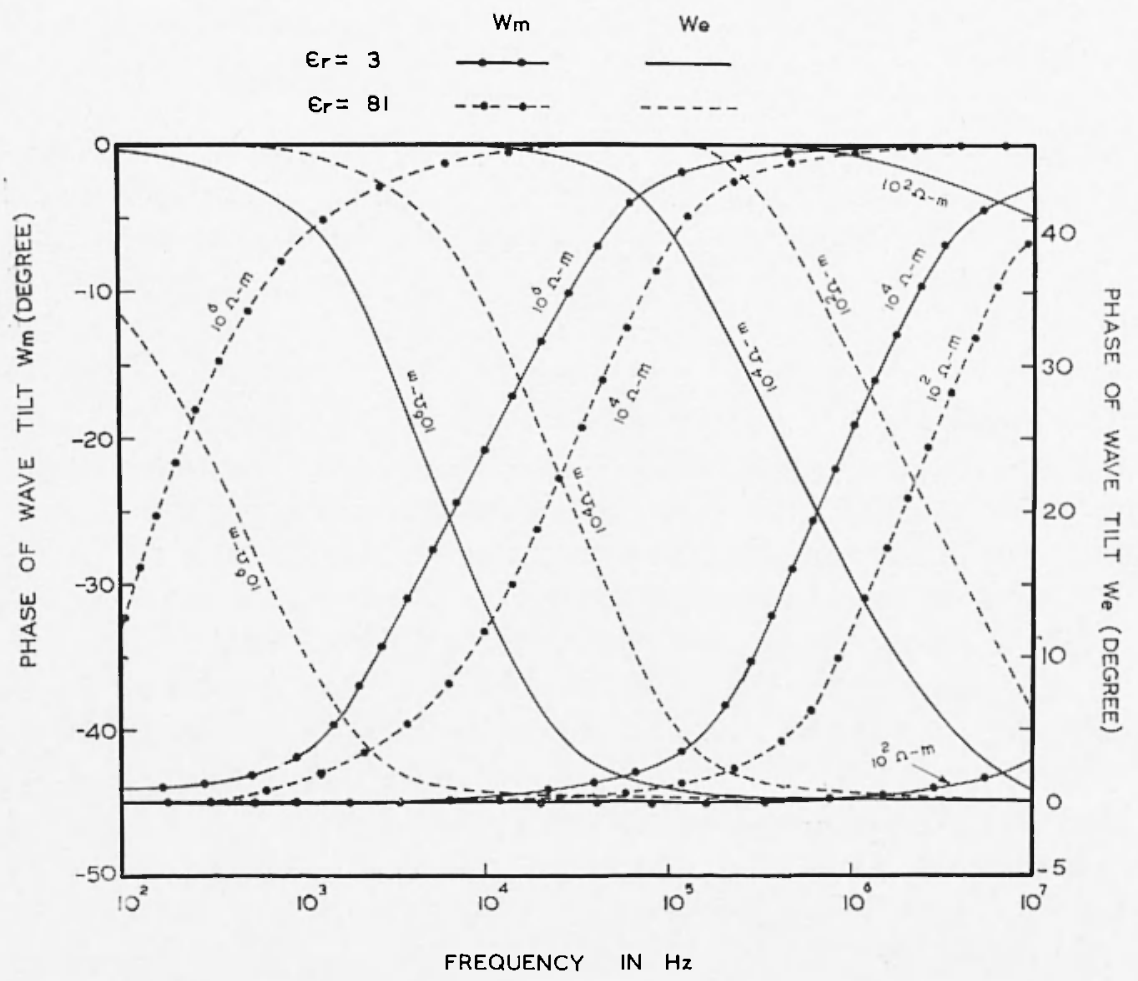

Fig. 10 - Variation of phase of wave-tilt with frequency. 
increases from $-45_{\mathrm{e}}$ to $0^{\circ}$ and shows a maximum sensitivity in certain frequency range. For resistivity values $10^{2}, 10^{4}$ and $10^{6}$ Ohm-m the frequency range of maximum sensitivity are $10^{6} \mathrm{~Hz}$ and beyond, $10^{4}-10^{7} \mathrm{~Hz}$ and $10^{2}-10^{4} \mathrm{~Hz}$ respectively. The change in dielectric produces a significant change in the phase angle in the entire frequency range.

\section{Conclusion}

The study of amplitude and phase of wave-tilt of TE and TM-mode have been carried out. The amplitude and phase of wave-tilt of TE-mode waves have been found to vary significantly with various parameters of the earth's subsurface. The amplitude and phase of wave-tilt of TE-mode maximise and vary rapidly in the lower frequency region, whereas for TM-mode wave is known to maximise and change rapidly in the higher frequency region. Studies of dependence of various parameters clearly show that the precise measurements of amplitude and phase can be used as diagnostic technique for resistivity survey of the subsurface. The present study clearly brings out the complimentary nature of characteristics in the two modes and shows that the simultaneous measurement of wave-tilt in both TM and TE-modes are capable of giving better information in the wider frequency range.

\section{AKNOWLEDGEMENT}

The author is grateful to CSIR, New Delhi for financial support. The author is grateful to Dr. T. Lal and Dr. J. Singh for their ispiration and stimulating discussions. 


\section{REFERENCES}

ARCONE S.A., 1977. - Investigation of an airbone resistivity survey conducted at very low frequency. CRRED Report 77-20, cold regions research. and Engineering laboratory, Hanover, New Hampshire, U.S.A.

ARCONE S.A., 1978. - Investigation of a VLF airbone resistivity survey conducted in northern Maine. "Geophysics ", 43, p. 1399-1417.

ARCONE S.A., 1979. - Resolution studies in airborne resistivity surveying at $V L F$. "Geophysics », 44, pp. 937-946.

Arcone S.A., Sellmann P.V., Delaney A.J., 1978. - Shallow electromagnetic geophysical investigations of permafrost. Proc. Third Intl. Conf. on Permafrost, p. 501-507.

Barlow H.E.M., Fernando W.M.G., 1956. - An investigation of the properties of radial surface waves launched over flat reactive surfaces. Proc. I.E.E., 103, p. 307-318.

Furutsu K., 1959. - On the excitation of the waves of proper solutions. Trans. I.R.E. Special supplement, AP-7, p. 209-218.

HACK F., 1908. - The propagation of electromagnetic waves over a plane conductor. "Ann. Phy.», 27, p. 43-45.

HoEKstra P., 1978. - Electromagnetic methods for mapping shallow permafrost. «Geophysics », 43, p. 782-787.

Hoenstra, P., McNeill D., 1973. - Electromagnetic probing of permafrost. Proc. 2nd International Conf. on Permafrost, p. 517-526.

Hoekstra P., Sellmann P.V., Delaney A.J., 1974. - Airborne resistivity mapping of permafrost near Fairbanks, Alaska. CRREL Research Report 324, ADA 000694.

Hoekstra P., Sellmann P.V., Delaney A.J., 1975. - Ground and airborne resistivity surveys of permafrost near Fairbanks, Alaska. "Geophysics ", 40 , p. $641-656$.

KING R.J., 1969. - EM wave propagation over a constant impedance plane. "Radio Science», 4, p. 255-268. 
KING R.J., 1974. - Groundwave propagation over horizontally layered anisotropic media. "Applied Physics », 5, p. 187-196.

KING R.J., 1976. - Wave-tilt measurement. IEEE Trans. Geo. Elect., 24, p. 115-119.

LyTLE R.J., LAGER D.L., 1976. - Theory relating to remote electromagnetic probing of a nonuniform-thickness coal seam. "Radio Science", 11 , p. $465-475$.

Lytle R.J., L Lager D.L., LAINe E.F., 1976 - Subsurface probing by high frequency measurements of the wave-tilt of electromagnetic suface waves. IEEE Trans. on "Geoscience Electronics", GE-14, p. 244-249.

McNeyll D., Hoekstra P., 1973. - In situ measurements on the conductivity and surface impedance of sea ice at VLF. "Radio Science ", 8, p. 23-30.

NoRTON K.A., 1937. - The propagation of radio waves over the surface of the earth and in the upper atmosphere: Part II. Proc. I.R.E., 25, p. 1203-1236.

SINHA A.K., 1979. - Influence of altitude and displacement currents on plane wave EM fields. "Geophysics», 42, p. 77-91.

SOMmerfield A., 1926. - Uber die Ausbreitung der wellen in der Drahtlosen telegraphie. "Ann. der Physik ", 81, p. 1135-1154.

Thiel D.V., 1979. - Relative wave-tilt measurement at VLF. "Geoexploration", 17, p. $285-292$.

TIIORTON B.S., 1979. - Inversion of the geophysical inverse problem for $n$ layers with nonumiqueness reduced to $n$ cases. "Geophysics", 44, p. 801-819.

WaIT J.R., 1957. - Excitation of surface waves on conducting dielectric clad, and corougated surfaces, "J. Res. Nat. Bur. Stand », 59, p. 365-377.

WaIT J.R., 1962. - Electromagnatic waves in stratified media. Pergamon Press, N.Y.

WARD S.H., 1967. - The electromagnetic method; chapt. II, Pt. c in book "Mining Geophysics», II, SEG Pubblication, Tulsa, USA.

ZENNECK J., 1907. - Uber die Fortflanzung ebner electromagnetischer Wellen einer ebenen Letterflache und ihre beziehung zur drahtlosen telegrapie. "Ann. Phys. ». Series 4, 23, p. 846-850. 